\title{
Conflictoplossing tussen ouders en adolescenten en delinquentie
}

Muriel D. van Doorn, Susan J. T. Branje en Wim H. J. Meeus

\section{SAMENVATTING}

In deze studie werd de relatie tussen conflictoplossing in de ouder-adolescentrelatie en delinquent gedrag bij adolescenten onderzocht. Adolescenten (gemiddelde leeftijd 13.3 jaar; $\boldsymbol{N}=284$ ) en hun beide ouders vulden vragenlijsten in over het gebruik van drie conflictoplossingsstijlen. Adolescenten vulden tevens een vragenlijst in over licht delinquent gedrag. Regressieanalyses lieten zien dat combinaties van conflictoplossingsstijlen van ouder en adolescent significant gerelateerd waren aan delinquentie. In relatie met vader bleek de 'demand-withdraw'-interactie gerelateerd aan delinquent gedrag bij adolescenten. In relatie met moeder bleek de interactie gekenmerkt door wederzijdse hostiliteit samen te hangen met delinquentie. De resultaten van dit onderzoek laten zien dat het belangrijk is om combinaties van conflictoplossingsstijlen van adolescent en ouder te onderzoeken.

\section{Inleiding}

Conflicten tussen ouders en adolescenten komen het meest voor in de vroege adolescentie (Laursen, Coy \& Collins, I998). In deze periode zijn adolescenten op zoek naar meer autonomie. Echter, aangezien ouders en adolescenten verschillende verwachtingen hebben over het moment en de mate waarin adolescenten zelfstandig beslissingen mogen nemen, zijn conflicten hierover onvermijdelijk (Collins, Laursen, Mortensen, Luebker \& Ferreira, I997; Deković, Noom \& Meeus, I997). Of conflicten functioneel of disfunctioneel zijn, hangt tot op zekere hoogte af van de manier waarop er met deze conflicten wordt omgegaan. Wanneer conflicten op een constructieve manier worden opgelost, gaat dit samen met een betere aanpassing van adolescenten (Collins \& Laursen, I992), terwijl conflicten die op een disfunctionele manier worden

Dr. M. D. van Doorn is als postdoc verbonden aan de Onderzoeksgroep Adolescentie van de Universiteit Utrecht, Postbus 80140, 3508 Tc Utrecht. E-mail: m.d.vandoorn@uu.nl.

Dr. S. J. T. Branje is als universitair hoofddocent verbonden aan de Onderzoeksgroep Adolescentie van de Universiteit Utrecht.

Prof. dr. W. H. J. Meeus is als hoogleraar verbonden aan de Onderzoeksgroep Adolescentie van de Universiteit Utrecht. 
opgelost, aanleiding geven tot probleemgedrag van adolescenten. In deze studie onderzoeken we zowel de manier waarop adolescenten conflicten met hun ouders oplossen als de manier waarop ouders conflicten met hun adolescenten oplossen en gaan we na in hoeverre de stijlen van conflictoplossing van adolescenten en ouders samenhangen met delinquentie bij adolescenten.

Het sociale probleemoplossingsmodel (Chang, D’Zurilla \& Sanna, 2004) laat zien waarom het belangrijk is om te kijken naar de relatie tussen conflictoplossingsstijlen van adolescenten, hun ouders en externaliserend gedrag van adolescenten zoals delinquentie. Volgens dit model zullen adolescenten met meer probleemoplossingsvaardigheden op een meer gepaste en adaptieve manier op conflictsituaties reageren en niet met externaliserend gedrag. Ook zullen ouders met meer probleemoplossingsvaardigheden hun adolescenten helpen om buitenshuis op een meer adaptieve manier met problemen om te gaan en zullen deze ouders waarschijnlijk op een effectievere manier met externaliserend gedrag - zoals criminele gedragingen - van hun kind omgaan (Jaffee \& D’Zurilla, 2003). Ook het coërcieve model van Patterson (I982, I995) stelt dat adolescenten die van hun ouders leren om dwingend of vijandig gedrag te gebruiken in hun onderlinge interacties, een grotere kans hebben om antisociaal en delinquent gedrag te vertonen en zich bovendien hetzelfde zullen gedragen in hun interacties met andere mensen (Conger, Ge, Elder, Lorenz \& Simons, I994; Dishion, Patterson \& Kavanagh, I992). Dat de relatie tussen conflictoplossingsstijlen en delinquentie van belang is, blijkt verder uit gezinsinterventies die gericht zijn op het behandelen en voorkomen van probleemgedrag bij adolescenten. Deze interventies bestaan vaak uit trainingen in conflictoplossing voor zowel ouders als adolescenten (Robin \& Foster, I989). Bovendien laat onderzoek zien dat een combinatie waarbij zowel de ouder als de adolescent training krijgt in conflictoplossing samenhangt met minder probleemgedrag dan wanneer een van de twee interventies op zichzelf gegeven wordt (Kazdin, Siegel \& Bass, I992).

In deze studie zullen we bekijken of bovenstaande theoretische modellen ook van toepassing zijn op kleine criminele gedragingen van adolescenten. We onderscheiden drie conflictoplossingsstijlen (Kurdek, I994):

- ruzie maken, gekenmerkt door verbaal agressief, aanvallend, boos en defensief gedrag;

- positief probleemoplossen, gekenmerkt door onderhandelen en compromissen sluiten;

- terugtrekken, gekenmerkt door het probleem vermijden en niet verder willen praten.

\section{Conflictoplossingsstijlen van adolescenten en delinquentie}

Drie studies vonden bewijs voor een relatie tussen de conflictoplossingsstijl ruzie maken en delinquent gedrag: Rubenstein en Feldman (I993) vonden dat jongens die regelmatig aanvallend reageerden op ouder-adolescentconflicten een groter risico liepen om delinquent gedrag te gaan vertonen. Deze relatie was onafhankelijk van het aantal conflicten met de ouders. Het gebruik van een meer impulsieve of roekeloze conflictoplossingsstijl bleek ook gerelateerd te zijn aan meer delinquentie bij adolescenten (Jaffee \& D'Zurilla, 2003). Bovendien bleek dat bij preadolescenten meer negatief beladen conflicten sterker gerelateerd waren aan delinquent gedrag (Sander, Dadds, Johnston \& Cash, I992). Wat betreft de vermijdende conflictoplossingsstijl 
terugtrekken vonden we inconsistente resultaten: terwijl één studie vond dat meer vermijding tijdens conflicten samenhing met meer delinquentie (Jaffee \& D’Zurilla, 2003), repliceerde een andere studie bij jongens dit resultaat niet (Rubenstein \& Feldman, I993). Deze laatste studie vond ook geen relatie tussen het gebruik van een constructieve stijl en delinquentie, na gecontroleerd te hebben voor het aantal conflicten (Rubenstein \& Feldman, I993). Echter, onderzoek bij preadolescenten vond wél dat delinquente kinderen de constructieve conflictoplossingsstijlen minder gebruikten (Sanders e.a., I992).

\section{Conflictoplossingsstijlen van ouders en delinquentie}

Naast de conflictoplossingsstijlen die adolescenten gebruiken in conflicten met hun ouders, is het belangrijk voor de aanpassing van de adolescent om te kijken naar de conflictoplossingsstijlen die hun ouders gebruiken. Het gebruik van een vijandige stijl door ouders bleek gerelateerd aan meer delinquentie, zowel cross-sectioneel (Conger, Conger, Elder, Lorenz, Simons \& Whitbeck, I992, I993) als longitudinaal (Ge, Best, Conger \& Simons, I996). In gezinnen met delinquente adolescenten bleken moeders minder constructieve conflictoplossing te gebruiken dan in gezinnen met niet-delinquente adolescenten. Dit verschil werd niet gevonden voor vaders (Borduin, Henggeler, Hanson \& Pruitt, I985). Ook bleken lagere niveaus van constructieve conflictoplossing van moeders gedurende de vroege adolescentie ernstig delinquent gedrag tijdens de jongvolwassenheid te voorspellen (Klein, Forehand, Armistead \& Long, I997). Deze relatie werd niet gevonden voor minder ernstige delinquente gedragingen. Ook Jaffee en D'Zurilla (2003) vonden geen significante relaties tussen het gebruik van drie conflictoplossingsstijlen door vaders en moeders (een impulsieve, roekeloze stijl, een vermijdende stijl en een constructieve stijl) en delinquentie bij adolescenten.

\section{Combinaties van conflictoplossingsstijlen van adolescenten en ouders en delinquentie}

Niet alleen de conflictoplossingsstijlen die adolescenten en ouders onafhankelijk van elkaar gebruiken, maar ook bepaalde combinaties van deze stijlen kunnen gerelateerd zijn aan delinquentie. Volgens het coërcieve model van Patterson (I982) wordt delinquent gedrag bij adolescenten sterk beïnvloed door ervaringen in het gezin, waarbij ouders en adolescenten elkaar voortdurend wederzijds beïnvloeden. Dit komt overeen met theorieën die bidirectionaliteit (ofwel wederzijdse beïnvloeding) in ouder-adolescentrelaties benadrukken (Hinde, I997; Lollis \& Kuczynski, I997; Staffford \& Bayer, I993). Daarom is het belangrijk om niet alleen de conflictoplossingsstijlen van adolescenten en ouders afzonderlijk in het onderzoek mee te nemen, maar om ook combinaties van conflictoplossingsstijlen van ouders en adolescenten te onderzoeken en te bekijken hoe deze combinaties samenhangen met delinquentie.

Volgens het coërcieve model maken delinquente kinderen en adolescenten vaak deel uit van een gezinssysteem dat gekenmerkt wordt door wederzijdse hostiliteit (Dadds, Sanders, Morrison \& Rebgetz, I992; Patterson, I982, I995). Dit interactiepatroon wordt gekenmerkt door ouders en kinderen die zich begeven in coërcieve ofwel dwingende interacties. Er zijn indicaties dat dit patroon meer voorkomt bij interacties tussen adolescenten en moeders dan tussen adolescenten en vaders. Moeders uit probleemgezinnen bleken met meer negatieve en minder positieve conflictoplossingsstij- 
len te reageren op negatief gedrag van de adolescent dan moeders uit controlegezinnen, en adolescenten uit probleemgezinnen bleken op hun beurt met meer negatief gedrag en minder positief gedrag te reageren op negatief gedrag van moeders dan adolescenten uit de controlegezinnen. Er werd geen verschil gevonden tussen probleemgezinnen en controlegezinnen in de manier waarop vaders en adolescenten op elkaars negatieve gedrag reageerden (Krinsley \& Bry, I99I). Tot slot vond ook een andere studie dat delinquente kinderen geneigd waren het negatieve, aversieve gedrag van hun moeders te beantwoorden met datzelfde gedrag (Sanders e.a., I992). In deze studie zullen we onderzoeken of de combinatie waarbij zowel adolescenten als ouders meer ruzie maken, samenhangt met meer delinquentie.

Een combinatie van conflictoplossingsstijlen door twee personen in een relatie die veel bestudeerd is, is het zogenaamde 'demand-withdraw'-patroon (Christensen \& Heavey, I990; Kurdek, I995). In onderzoek naar huwelijksrelaties blijkt dit 'demandwithdraw'-patroon, waarbij de vrouw ruzie maakt en de man zich terugtrekt, voor zowel mannen als vrouwen een verlaging van de huwelijkssatisfactie te voorspellen (Kurdek, I995). Recentelijk is dit patroon ook onderzocht in de ouder-adolescentrelatie. De 'demand-withdraw'-combinatie bleek gerelateerd te zijn aan probleemgedrag van de adolescent. De combinatie van een ouder die ruzie maakt en een adolescent die zich terugtrekt, hing samen met een hoger alcohol- en drugsgebruik bij de adolescent. De combinatie waarin de adolescent ruzie maakt en de ouder zich terugtrekt, bleek samen te hangen met een lager zelfvertrouwen van de adolescent (Caughlin \& Malis, 2004b). Aangezien studies laten zien dat het 'demand-withdraw'-patroon een ineffectieve manier van conflictoplossing is (Caughlin \& Malis, 2004a, 2004b; Kurdek, I995), willen wij in deze studie onderzoeken of deze combinatie van stijlen in de ouder-adolescentrelatie ook gerelateerd is aan licht delinquente gedragingen. Meer specifiek zullen wij onderzoeken of de combinatie van meer ruzie maken door de adolescent en meer terugtrekken door de ouder en de combinatie van meer ruzie maken door de ouder en meer terugtrekken door de adolescent gerelateerd is aan delinquentie.

Samenvattend: we zullen onderzoeken hoe de conflictoplossingsstijlen van adolescenten, ouders en combinaties van conflictoplossingsstijlen van adolescenten en ouders samenhangen met delinquent gedrag. We verwachten dat wanneer adolescenten meer ruzie maken, dit zal samenhangen met meer delinquent gedrag. We verwachten ook dat meer ruzie maken van ouders zal samenhangen met meer delinquent gedrag. Tot slot verwachten we dat de combinatie van ruzie maken door zowel adolescenten als ouders samenhangt met meer delinquentie, met name in de adolescentmoederrelatie.

Aangezien zowel de frequentie van conflicten als de intensiteit van conflicten gerelateerd blijkt te zijn aan probleemgedrag van adolescenten (Barber \& Delfabbro, 2000; Borduin e.a., I985; Sanders e.a., I992; Shek, I997, 1998; Tesser, Forehand, Brody \& Long, I989), zullen we in onze analyses hiervoor controleren. We zullen ook controleren voor het geslacht van de adolescent, omdat bekend is dat jongens over het algemeen hoger scoren op delinquentie dan meisjes (Coie \& Dodge, I998; Farrington, 2004). Aangezien we in onze studie gebruik maken van een normale populatie, richten we ons op kleine criminele gedragingen. 


\section{Methode}

\section{Respondenten}

Aan dit onderzoek namen 284 adolescenten deel, van wie I42 jongens (50\%). De gemiddelde leeftijd van de adolescenten was I3.3 jaar (range I2-I5 jaar, $S D=.50$ ); de gemiddelde leeftijd van vaders en moeders was respectievelijk 46.8 jaar (range 35-65 jaar, $S D=5 . \mathrm{I}$ ) en 44.3 jaar (range 34-55 jaar, $S D=4 . \mathrm{I}$ ). Alle adolescenten waren Nederlanders en woonden bij beide ouders. Verschillende opleidingsniveaus waren vertegenwoordigd, met circa 5 I\% op vwo-niveau, $36 \%$ op havo-niveau en $14 \%$ op vmbo/ mbo-niveau. Van de vaders had I.8\% de middelbare school niet afgemaakt, had 2I.I\% lager beroepsonderwijs, middelbaar algemeen voortgezet onderwijs of hoger algemeen voortgezet onderwijs gevolgd, had 4I.9\% middelbaar of hoger beroepsonderwijs gevolgd en $35.3 \%$ wetenschappelijk onderwijs. Voor de moeders waren deze percentages respectievelijk .40, 35.5, 44.4 en I9.7.

De data van deze studie komen uit de gezinssteekproef, een substeekproef van het longitudinale onderzoeksproject Conflict and Management of Relationships (CONAMORE; Meeus e.a., 2004). In dit longitudinale onderzoeksproject participeren jaarlijks 938 vroege adolescenten (gemiddelde leeftijd I2.4 jaar, $S D=.60$ ) en 393 middenadolescenten (gemiddelde leeftijd I6.7 jaar, $S D=.80$ ) van verschillende scholen in de provincie Utrecht gedurende vijf metingen. Op het eerste meetmoment ontvingen de Nederlandse vroege adolescenten een brief met een uitnodiging om met beide ouders te participeren in een additioneel onderzoek met jaarlijkse huisbezoeken. Uiteindelijk werden 323 tweeoudergezinnen at random geselecteerd om mee te doen vanaf de tweede 'wave' van de hoofdstudie. Voor het huidige onderzoek waren data van de eerste meetronde van de gezinssteekproef beschikbaar. In onze analyses hebben we alleen gezinnen meegenomen met complete data op deze meetronde, waardoor we uitkwamen op data van 284 adolescenten en hun beide ouders.

\section{Procedure}

Voorafgaand aan het onderzoek kregen zowel adolescenten als hun ouders schriftelijke informatie. Als de adolescent wilde deelnemen aan het onderzoek, werd schriftelijke toestemming gevraagd aan zowel adolescent als ouders. Interviewers bezochten de scholen en vroegen deelnemende adolescenten om na schooltijd naar een klaslokaal te komen en een reeks vragenlijsten in te vullen. Interviewers bezochten de gezinnen ook thuis. Gedurende deze huisbezoeken vulden adolescenten nog extra vragenlijsten in en werden beide ouders verzocht een reeks vragenlijsten in te vullen. Geheimhouding van de antwoorden werd gegarandeerd. Gezinnen ontvingen 27 euro voor hun deelname en de adolescenten ontvingen voor hun deelname op school nog eens io euro.

\section{Meetinstrumenten}

Conflictfrequentie. Het aantal conflicten met vaders en moeders werd gemeten met de Interpersonal Conflict Questionnaire (ICQ; Laursen, I993, I995). Deze lijst bestaat uit 35 conflictonderwerpen die beoordeeld werden op een vijfpunts-Likert-schaal ( $\mathrm{I}=$ nooit; 5 = vaak). Adolescenten beoordeelden voor elk item hoe vaak ze gedurende de afge- 
lopen week conflicten met vader en moeder over een bepaald onderwerp hadden gehad. Items waren bijvoorbeeld: 'Privacy, alleen willen zijn', 'Te veel tv kijken, of de computer of telefoon te veel gebruiken' en 'Niet doen wat je gevraagd wordt'. De 35 items werden gemiddeld om tot een frequentiescore te komen. Cronbachs alfa's waren .94 voor zowel conflicten met vaders als met moeders.

Conflictintensiteit. Conflictintensiteit werd tevens gemeten met de Laursens Interpersonal Conflict Questionnaire (ICQ; Laursen, I993, I995). Adolescenten gaven op een vijfpunts-Likert-schaal ( $\mathrm{I}=$ vriendelijk; $5=$ boos) aan hoe ze zich in het algemeen gedurende conflicten met vaders en moeders voelden en hoe ze zich erna voelden. Bovendien moesten ze op een vijfpunts-Likert-schaal aangeven hoe conflicten de relatie met hun vaders en moeders beïnvloedden, variërend van 'maakt de relatie beter' tot 'maakt de relatie slechter'. Het gemiddelde van deze drie items vormde een intensiteitsscore.

Conflictoplossingsstijlen. Conflictoplossingsstijlen werden gemeten met Kurdeks Conflict Resolution Style Inventory (CRSI; Kurdek, I994). In deze studie werden drie conflictoplossingsstijlen onderscheiden: ruzie maken, terugtrekken en positief probleemoplossen. Adolescenten beoordeelden hoe vaak ze een specifieke conflictoplossingsstijl gebruikten tijdens conflicten met vaders en moeders. Bovendien beoordeelden vaders en moeders hoe vaak ze een specifieke conflictoplossingsstijl gebruikten tijdens conflicten met adolescenten. Elke stijl werd gemeten met vijf items die beoordeeld werden op een vijfpunts-Likert-schaal ( $\mathrm{I}=$ nooit; 5 = altijd). Een voorbeeld-item van ruzie maken is: 'Woest worden en mijn beheersing verliezen.' Terugtrekken werd gemeten door bijvoorbeeld: 'Stoppen, er niet meer op in gaan en weigeren om nog verder te praten.' Een voorbeeld-item van positief probleemoplossen is: 'Oplossingen proberen te vinden die voor ons alle twee acceptabel zijn.' Cronbachs alfa's varieerden van .79-.90 voor conflictoplossing van adolescent met vader, van $.75^{-.84}$ voor conflictoplossing van adolescent met moeder, van .69-.77 voor conflictoplossing van vader met adolescent en van .68-.79 voor conflictoplossing van moeder met adolescent.

Delinquentie. Delinquentie werd gemeten met behulp van een vragenlijst bestaande uit zestien items (Baerveldt, Van Rossem \& Vermande, 2003). Adolescenten werd gevraagd om op een vierpuntsschaal ( $\mathrm{I}=$ nooit; $4=$ viermaal of vaker) te beoordelen hoe vaak ze bepaalde vormen van kleine criminaliteit vertoond hadden gedurende de laatste twaalf maanden (bijv. 'Een brandje aangestoken, 'Opzettelijk iets vernield op straat', 'Met stiften of met een spuitbus dingen bewerkt', 'Iets uit een winkel gestolen' en 'Betrokken geweest bij een gevecht'). Het gemiddelde op deze zestien items vormde een delinquentiescore. Cronbachs alfa voor deze schaal was .8o. Factoranalyse op de hele steekproef laat zien dat er één factor uitkomt, waarbij de ladingen hoger zijn dan .4I (Meeus e.a., 2004).

\section{Analyseplan}

Om te onderzoeken hoe conflictoplossingsstijlen van adolescenten en ouders samenhingen met delinquentie, hebben we afzonderlijke hiërarchische multipele re- 
gressieanalyses gedaan voor de adolescent-vaderrelatie en adolescent-moederrelatie. In deze regressieanalyses werden in de eerste stap demografische variabelen ingevoerd, zoals geslacht van de adolescent, opleidingsniveau van de adolescent en opleidingsniveau van vader of moeder. We controleerden voor de frequentie van conflicten en voor conflictintensiteit in stap 2. Om te onderzoeken hoe de conflictoplossingsstijlen van adolescenten met vaders en moeders samenhingen met delinquentie, voegden we ruzie maken, terugtrekken en positief probleemoplossen van adolescenten met vader of moeder in stap 3 toe. Ruzie maken, terugtrekken en positief probleemoplossen van vaders en moeders met adolescenten werden in stap 4 toegevoegd. Ten slotte, om te onderzoeken of bepaalde combinaties van conflictoplossingsstijlen gerelateerd waren aan delinquentie, werden in stap 5 de twee 'demand-withdraw'-combinaties en de combinatie waarin zowel ouders als adolescenten ruzie maken toegevoegd. Het laatste model, met alle voorspellers, werd gebruikt voor het beantwoorden van de onderzoeksvragen (voor details van eerdere modellen zie Van Doorn, Branje \& Meeus, 2009).

Voordat we interactietermen maakten, werden de scores op de conflictoplossingsstijlen gecentreerd door van elke individuele score het gemiddelde af te trekken, zodat multicollineariteit tussen de hoofdeffecten en interactietermen voorkomen werd (Jaccard, Turrisi \& Wan, I990). Significante interacties werden zichtbaar gemaakt door het berekenen van de helling van delinquentie op de conflictoplossingsstijl van één relatiepartner, voor verschillende niveaus van de conflictoplossingsstijl van de andere relatiepartner. Meer specifiek berekenden we de helling wanneer de score van de andere relatiepartner op de conflictoplossingsstijl laag (d.w.z. meer dan één standaarddeviatie onder het gemiddelde), gemiddeld (d.w.z. tussen één standaarddeviatie boven en onder het gemiddelde) en hoog (meer dan één standaarddeviatie boven het gemiddelde) was.

\section{Resultaten}

Tabel I geeft de gemiddelden en standaarddeviaties weer van de variabelen in onze studie. De score op delinquentie is laag, wat te verwachten was aangezien de deelnemers uit een normale populatie kwamen.

De resultaten van de regressieanalyses zijn weergegeven in tabel 2 . In deze tabel wordt het uiteindelijke model gepresenteerd. Geslacht van de adolescent bleek significant gerelateerd aan delinquentie: jongens scoorden in onze steekproef significant hoger op delinquentie dan meisjes. Conflicten bleken ook positief gerelateerd aan delinquentie: adolescenten die meer conflicten hadden met vaders en moeders, scoorden ook hoger op delinquentie dan adolescenten die minder conflicten met vaders en moeders hadden. Conflictintensiteit bleek niet significant gerelateerd aan delinquentie.

In het uiteindelijke regressiemodel vonden we geen enkel significant hoofdeffect meer van de conflictoplossingsstijl van adolescenten. In de modellen zonder de interactietermen vonden we steeds een significant hoofdeffect van ruzie maken van adolescenten met vaders en moeders. Ruzie maken, terugtrekken en positief probleem- 
Tabel 1 Gemiddelden en standaarddeviaties van de conflictmaten en van delinquentie.

\begin{tabular}{lll} 
& \multicolumn{1}{l}{ Vaders $(N=284)$} & Moeders $(N=284)$ \\
\hline Conflictfrequentie & $M(S D)$ & $M(S D)$ \\
Conflictintensiteit & $1.64(.51)$ & $1.74(.52)$ \\
Ruzie maken door adolescenten & $2.79(.85)$ & $2.67(.75)$ \\
Terugtrekken van adolescenten & $1.32(.50)$ & $1.43(.54)$ \\
Positief probleemoplossen door adolescenten & $1.80(.77)$ & $1.94(.70)$ \\
Ruzie maken door ouders & $3.04(.98)$ & $3.17(.88)$ \\
Terugtrekken van ouders & $1.72(.48)$ & $1.75(.49)$ \\
Positief probleemoplossen door ouders & $1.66(.56)$ & $1.59(.54)$ \\
Delinquentie & $3.66(.58)$ & $4.01(.54)$ \\
\hline
\end{tabular}

Tabel 2 Relatie tussen conflictoplossingsstijlen van adolescenten en ouders en delinquentie (uiteindelijk model).

\begin{tabular}{|c|c|c|c|c|}
\hline Voorspellers & Delinq & & & \\
\hline & Vader & & Moeder & \\
\hline & $\beta$ & $\Delta R^{2}$ & $\beta$ & $\Delta R^{2}$ \\
\hline Geslacht van adolescent & $-.22^{* *}$ & & $-.21^{* *}$ & \\
\hline Opleidingsniveau van adolescent & .03 & & -.03 & \\
\hline Opleidingsniveau van vader/moeder & -.06 & & .01 & \\
\hline Stap 1 & & $.04^{* *}$ & & $.04 * *$ \\
\hline Conflictfrequentie met vader/moeder & $.25^{* *}$ & & $.26^{* *}$ & \\
\hline Conflictintensiteit met vader/moeder & .10 & & .01 & \\
\hline Stap 2 & & $.13^{* *}$ & & $.11^{* *}$ \\
\hline Ruzie maken door adolescent & .06 & & .10 & \\
\hline Terugtrekken van adolescent & .00 & & .00 & \\
\hline $\begin{array}{l}\text { Positief probleemoplossen door } \\
\text { adolescent }\end{array}$ & .06 & & .03 & \\
\hline Stap 3 & & .02 & & .01 \\
\hline Ruzie maken door vader/moeder & -.04 & & .05 & \\
\hline Terugtrekken van vader/moeder & .02 & & .02 & \\
\hline $\begin{array}{l}\text { Positief probleemoplossen door vader/ } \\
\text { moeder }\end{array}$ & -.06 & & .02 & \\
\hline Stap 4 & & .01 & & .01 \\
\hline A ruzie maken $\times \mathrm{V} / \mathrm{M}$ terugtrekken & $.16^{*}$ & & -.09 & \\
\hline A terugtrekken $\times \mathrm{V} / \mathrm{M}$ ruzie maken & .04 & & -.02 & \\
\hline A ruzie maken $\times \mathrm{V} / \mathrm{M}$ ruzie maken & .11 & & $.21^{* *}$ & \\
\hline Stap 5 & & $.06^{* *}$ & & $.03^{*}$ \\
\hline$R^{2}$ totaal & & $.25^{* *}$ & & $.20^{* *}$ \\
\hline
\end{tabular}

$\mathbf{A}=$ adolescent; $\mathbf{v}=$ vader $\mathbf{M}=$ moeder. 
oplossen van adolescenten bleken niet significant gerelateerd aan delinquentie. Hetzelfde gold voor de conflictoplossingsstijlen van ouders: ruzie maken, terugtrekken en positief probleemoplossen van ouders waren niet significant gerelateerd aan delinquentie.

De belangrijkste bevinding van het onderzoek was dat specifieke combinaties van stijlen van adolescenten en ouders gerelateerd waren aan delinquentie. Het 'demandwithdraw'-patroon, waarin adolescenten ruzie maken en vaders zich terugtrekken, hing significant samen met delinquentie. In figuur I is deze interactie weergegeven. De interactie liet zien dat meer ruzie maken van adolescenten het sterkst gerelateerd was aan meer delinquentie wanneer vaders zich vaker terugtrokken tijdens conflicten $(\beta=.53, p<$. OI). Meer ruzie maken van adolescenten bleek ook, maar iets minder sterk, significant samen te hangen met meer delinquentie wanneer vaders zich gemiddeld vaak terugtrokken tijdens conflicten $(\beta=.23, p<$.oI). Ten slotte bleek dat meer ruzie maken van adolescenten niet samenhing met delinquentie wanneer vaders zich minder vaak terugtrokken tijdens conflicten $(\beta=-.07, p>.05)$. Met andere woorden, delinquentie van adolescenten was het hoogst wanneer adolescenten vaker ruzie maakten en vaders zich vaker terugtrokken. Het 'demand-withdraw'-patroon waarbij vader ruzie maakt en de adolescent zich terugtrekt, bleek niet significant gerelateerd aan delinquentie. In de adolescent-moederrelatie bleken beide 'demand-withdraw'interacties niet significant samen te hangen met delinquentie.

Figuur 1 'Demand-withdraw'-interactie in de adolescent-vaderrelatie.

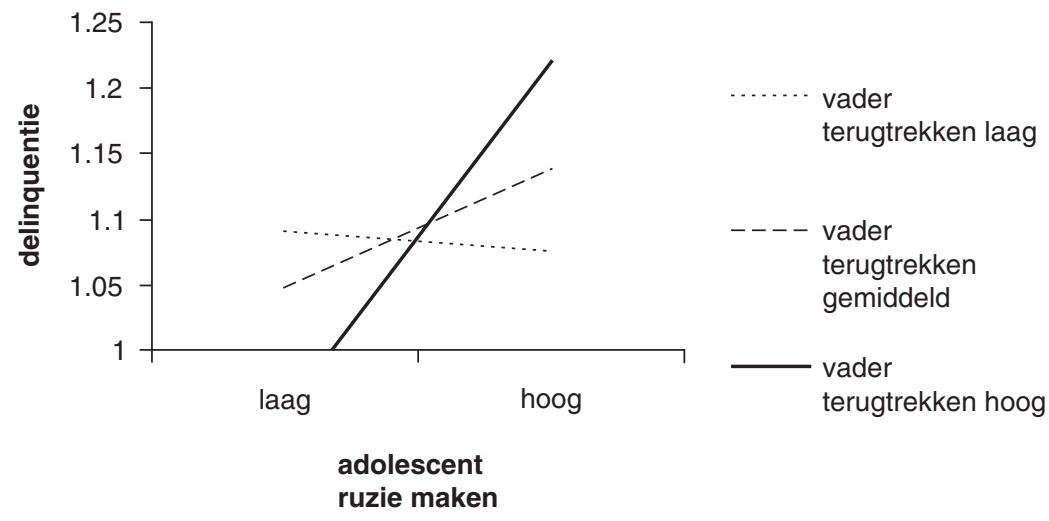

De interactie waarbij adolescenten en moeders ruzie maken, bleek ook significant samen te hangen met delinquentie, wat in overeenstemming was met onze verwachting wat betreft wederzijdse hostiliteit. Figuur 2 geeft deze interactie weer.

De interactie liet zien dat meer ruzie maken van adolescenten gerelateerd was aan meer delinquentie, met name wanneer moeders ook vaker ruzie makten $(\beta=.48, p<$ .оI). Meer ruzie maken van adolescenten bleek ook significant samen te hangen met meer delinquentie wanneer moeders gemiddeld meer ruzie maakten $(\beta=. \mathrm{I} 7, p<$. . I $)$. 


\section{Figuur 2 Wederzijdse hostiliteitsinteractie in de adolescent-moederrelatie.}

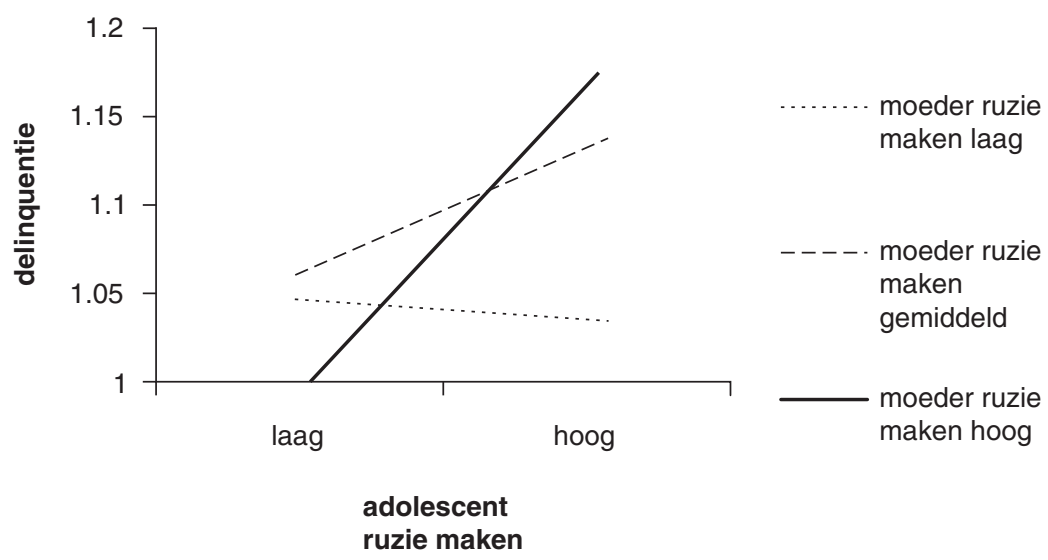

Ten slotte bleek dat meer ruzie maken van adolescenten niet samenhing met delinquentie wanneer moeders minder vaak ruzie maakten $(\beta=-.05, p>.05)$. Met andere woorden, delinquentie van adolescenten was het hoogst wanneer zowel adolescent als moeders vaker ruzie maakten. De interactie waarbij zowel adolescent als vaders ruzie maakten, bleek niet significant gerelateerd aan delinquentie.

\section{Discussie}

In deze studie onderzochten we hoe conflictoplossingsstijlen van zowel adolescenten als ouders samenhangen met licht delinquente gedragingen van adolescenten. De resultaten laten zien dat combinaties van conflictoplossingsstijlen die adolescenten en ouders gebruiken, samenhingen met delinquentie, wat in overeenstemming is met theorieën die veronderstellen dat met name de dynamiek van de interactie in ouderadolescentrelaties voorspellend is voor het gedrag van adolescenten (o.a. Hinde, I997; Lollis \& Kuczynski, ı997; Stafford \& Bayer, I993). We vonden dat ruzie maken door adolescenten met ouders het sterkst bleek samen te hangen met delinquent gedrag van de adolescent wanneer moeders ook ruzie maakten en wanneer vaders zich terugtrokken uit het conflict.

Wanneer we keken naar de relatie tussen conflictoplossingsstijlen van de adolescent en delinquentie, vonden we dat ruzie maken van adolescenten tijdens conflicten met ouders samenhing met meer delinquent gedrag. Dit is een indicatie dat adolescenten die deze ineffectieve stijl gebruiken ook meer delinquent gedrag vertonen. Eerder onderzoek toonde al aan adolescenten die een agressieve stijl gebruiken tijdens conflicten ook hoger scoorden op delinquentie (Jaffee \& D'Zurilla, 2003; Rubenstein \& Feldman, I993; Sanders e.a., I992). Adolescenten die tijdens conflicten met ouders ruzie maken, zijn duidelijk niet in staat om op een adequate manier met conflicten om te gaan. Volgens het sociale probleemoplossingsmodel zullen deze adolescenten ook 
minder passend reageren op conflictsituaties buitenshuis en kunnen zij daardoor in deze situaties delinquente gedragingen vertonen (Chang e.a., 2004; Jaffee \& D'Zurilla, 2003). We vonden dat de conflictoplossingsstijlen van ouders niet samenhingen met delinquent gedrag van de adolescent.

In zowel de adolescent-moederrelatie als de adolescent-vaderrelatie bleek er een bepaalde combinatie van conflictoplossingsstijlen gerelateerd aan delinquentie: in de adolescent-moederrelatie bleek de combinatie waarbij zowel adolescenten als moeders ruzie maakten significant gerelateerd aan delinquentie. Adolescenten vertoonden dus meer delinquent gedrag wanneer er sprake was van meer coërcieve, dwingende interacties tussen adolescenten en moeders. In de adolescent-vaderrelatie bleek deze interactie niet significant. De bevinding dat deze interactie van wederzijdse hostiliteit alleen in de adolescent-moederrelatie gerelateerd bleek aan delinquentie, komt overeen met eerder onderzoek naar conflictinteracties in probleemgezinnen (Krinsley \& Bry, I99I; Sanders e.a., I992).

In de adolescent-vaderrelatie bleek de combinatie waarbij de adolescent ruzie maakte en de vader zich terugtrok significant gerelateerd aan delinquentie. Met andere woorden, adolescenten vertoonden meer delinquent gedrag wanneer zij meer ruzie maakten en wanneer vaders zich meer terugtrokken tijdens conflicten. Terugtrekken van vaders tijdens conflicten zou beschouwd kunnen worden als gebrek aan betrokkenheid en geen tot weinig moeite doen om conflicten uit te praten. Een studie onder I5-I6jarige adolescenten liet zien dat het je minder geliefd voelen bij je ouder en weinig betrokkenheid van de ouder sterker gerelateerd was aan delinquent gedrag voor de relatie met vader dan voor de relatie met moeder (Johnson, I987). Bovendien zou de relatie tussen terugtrekken van vaders en delinquentie verklaard kunnen worden doordat terugtrekkende vaders hun kind wellicht minder in de gaten houden of monitoren dan vaders die zich minder terugtrekken tijdens conflicten. Het blijkt namelijk dat minder monitoren en supervisie door ouders gerelateerd is aan meer delinquentie bij adolescenten (Patterson \& Stouthamer-Loeber, I984). In tegenstelling tot onderzoek naar de relatie tussen het 'demand-withdraw'-patroon en middelengebruik (Caughlin \& Malis, 2004b), vonden wij dat de combinatie van ruzie maken door ouders en terugtrekken van de adolescent niet gerelateerd was aan delinquentie.

Het blijkt dus dat ouders het effect van een negatieve conflictoplossingsstijl van de adolescent kunnen modereren. Ruzie maken van de adolescent hangt samen met meer delinquentie wanneer dit gebeurt in combinatie met meer ruzie maken door moeders en meer terugtrekken door vaders. Echter, wanneer moeders zeer weinig gebruik maken van ruzie en vaders zeer weinig gebruik maken van terugtrekken, hangt ruzie maken van de adolescent niet significant samen met delinquent gedrag. Voor de hulpverlening aan gezinnen betekent dit dat er aandacht moet worden besteed aan de manier waarop adolescenten en ouders hun onderlinge conflicten oplossen. De manier waarop ouders reageren op een ruziemakende adolescent blijkt van belang: voor vaders blijkt het belangrijk om betrokken te blijven bij het conflict en zich niet terug te trekken, terwijl moeders tijdens conflicten minder ruzie moeten maken met de adolescent.

Onze studie kent een aantal beperkingen. Ten eerste hebben we alleen gebruik gemaakt van zelfrapportages om conflicten, conflictintensiteit, conflictoplossingsstijlen en delinquentie te meten. Beter zou het zijn geweest wanneer we een combinatie 
van informanten hadden gebruikt, bijvoorbeeld een combinatie van adolescent-, ouderen leraarrapportages. Een andere beperking betreft de generaliseerbaarheid van onze bevindingen. In onze steekproef zaten relatief hoog opgeleide, autochtone jongeren, afkomstig uit intacte, goed functionerende gezinnen. Voor vervolgonderzoek zou het interessant zijn om te onderzoeken of onze resultaten ook bij allochtone, minder goed functionerende of gescheiden gezinnen gevonden worden. Ten slotte is de correlationele aard van het onderzoek een beperking. De manier waarop adolescenten en ouders met conflicten omgaan zou ook een gevolg kunnen zijn van delinquent gedrag van de adolescent. Longitudinaal onderzoek is nodig om te onderzoeken of de manier waarop conflicten worden opgelost delinquentie voorspelt of dat delinquent gedrag door de adolescent de keuze van bepaalde conflictoplossingsstijlen van ouder en adolescent voorspelt.

\section{Tot besluit}

Concluderend kunnen we zeggen dat onze studie aantoont dat combinaties van conflictoplossingsstijlen van adolescenten en ouders gerelateerd zijn aan delinquent gedrag bij adolescenten. In de relatie met vaders vonden we dat het 'demand-withdraw'-patroon, gekenmerkt door meer ruzie maken door de adolescent en meer terugtrekken door vaders, significant samenhing met meer delinquentie. In de relatie met moeders vonden we bewijs voor wederkerige hostiliteit: de combinatie waarbij zowel moeders als adolescenten meer ruzie maakten was significant gerelateerd aan meer delinquentie. Deze resultaten benadrukken dat het belangrijk is om combinaties van conflictoplossingsstijlen van adolescenten en ouders te onderzoeken.

\section{Literatuur}

Baerveldt, C., Van Rossem, R., \& Vermande, M. (2003). Pupils' delinquency and their social networks: A test of some networks assumptions of the ability and inability models of delinquency. Netherlands Journal of Social Sciences, 39, 107-125.

Barber, J. G., \& Delfabbro, P. (2000). Predictors of adolescent adjustment: Parent-peer relationships and parent-child conflict. Child and Adolescent Social Work Journal, 17, 275-288.

Borduin, C. M., Henggeler, S. W., Hanson, C. L., \& Pruitt, J. A. (I985). Verbal problem solving in families of father-absent and father-present delinquent boys. Child and Family Behavior Therapy, 7, 5I-63.

Caughlin, J. P., \& Malis, R. S. (2004a). Demand/withdraw communication between parents and adolescents as a correlate of relational satisfaction. Communication Reports, 17, 59-7I.

Caughlin, J. P., \& Malis, R. S. (2004b). Demand/withdraw communication between parents and adolescents: Connections with self-esteem and substance use. Journal of Social and Personal Relationships, 21, I25-I48.

Chang, E. C., D’Zurilla, T. J., \& Sanna, L. J. (Eds.) (2004). Social problem solving: Theory, research, and training. Washington, DC: American Psychological Association.

Christensen, A., \& Heavey, C. L. (I990). Gender and social structure in the demand/withdraw pattern of marital conflict. Journal of Personality and Social Psychology, 59, 73-8I.

Coie, J. D., \& Dodge, K. A. (I998). Aggression and antisocial behavior. In W. Damon (Series Ed.) \& N. 
Eisenberg (Vol. Ed.), Handbook of child psychology, Vol. 3. Social, emotional, and personality development (5th ed., pp. 779-862). New York: Wiley.

Collins, W. A., \& Laursen, B. (I992). Conflicts and relationships during adolescence. In C. U. Shantz \& W. W. Hartup (Eds.), Conflict in child and adolescent development (pp. 2I6-24I). New York: Cambridge University Press.

Collins, W. A., Laursen, B., Mortensen, N., Luebker, C., \& Ferreira, M. (I997). Conflict processes and transitions in parent and peer relationships: Implications for autonomy and regulation. Journal of Adolescent Research, 12, I78-198.

Conger, R. D., Conger, K. J., Elder, G. H., Jr., Lorenz, F. O., Simons, R. L., \& Whitbeck, L. B. (I992). A family process model of economic hardship and adjustment of early adolescent boys. Child Development, 63, 52654I.

Conger, R. D., Conger, K. J., Elder, G. H., Jr., Lorenz, F. O., Simons, R. L., \& Whitbeck, L. B. (I993). Family economic stress and adjustment of early adolescent girls. Developmental Psychology, 29, 206-2I9.

Conger, R. D., Ge, X., Elder, G. H., Jr., Lorenz, F. O., \& Simons, R. L. (I994). Economic stress, coercive family process, and developmental problems of adolescents. Child Development, 65, 54I-56I.

Dadds, M. R., Sanders, M. R., Morrison, M., \& Rebgetz, M. (I992). Childhood depression and conduct disorder, Pt. II. An analysis of family interaction patterns in the home. Journal of Abnormal Psychology, 101, 505-513.

Deković, M., Noom, M. J., \& Meeus, W. (I997). Expectations regarding development during adolescence: Parental and adolescent perceptions. Journal of Youth and Adolescence, 26, 253-272.

Dishion, T. J., Patterson, G. R., \& Kavanagh, K. A. (I992). An experimental test of the coercion model: Linking theory, measurement, and intervention. In J. McCord \& R. E. Tremblay (Eds.), Preventing antisocial behavior: Interventions from birth through adolescence (pp. 253-282). New York: The Guilford Press.

Farrington, D. (2004). Conduct disorder, aggression, and delinquency. In R. Lerner \& L. Steinberg (Eds.), Handbook of adolescent psychology (2nd Ed.). New York: Wiley.

Ge, X., Best, K. M., Conger, R. D., \& Simons, R. L. (I996). Parenting behaviors and the occurrence and cooccurrence of adolescent depressive symptoms and conduct problems. Developmental Psychology, 32, 7I773I.

Hinde, R. A. (I997). Relationships: A dialectic perspective. Hove: Psychology Press.

Jaccard, J., Turrisi, R., \& Wan, C. K. (I990). Interaction effects in multiple regression. Newbury Park: Sage.

Jaffee, W. B., \& D'Zurilla, T. J. (2003). Adolescent problem solving, parent problem solving, and externalizing behavior in adolescents. Behavior Therapy, 34, 295-3II.

Johnson, R. E. (I987). Mother's versus father's role in causing delinquency. Adolescence, 22, 305-3I5.

Kazdin, A. E., Siegel, T. C., \& Bass, D. (I992). Cognitive problem-solving skills training and parent management training in the treatment of antisocial behavior in children. Journal of Consulting and Clinical Psycho$\log$, 60, 733-747.

Klein, K., Forehand, R., Armistead, L., \& Long, P. (I997). Delinquency during the transition to early adulthood: Family and parenting predictors from early adolescence. Adolescence, 32, 6I-80.

Krinsley, K. E., \& Bry, B. H. (I991). Sequential analyses of adolescent, mother, and father behaviors in distressed and nondistressed families. Child and Family behavior therapy, 13, 45-62.

Kurdek, L. A. (I994). Conflict resolution styles in gay, lesbian, heterosexual nonparent, and heterosexual parent couples. Journal of Marriage and the Family, 56, 705-722.

Kurdek, L. A. (I995). Predicting change in marital satisfaction from husbands' and wives' conflict resolution styles. Journal of Marriage and the Family, 57, I53-164. 
Laursen, B. (I993). The perceived impact of conflict on adolescent relationships. Merrill-Palmer Quarterly, 39, 535-550.

Laursen, B. (I995). Conflict and social interaction in adolescent relationships. Journal of Research on Adolescence, 5, 55-70.

Laursen, B., Coy, K. C., \& Collins, W. A. (I998). Reconsidering changes in parent-child conflict across adolescence: A meta-analysis. Child Development, 69, 8I7-832.

Lollis, S., \& Kuczynski, L. (I997). Beyond one hand clapping: Seeing bidirectionality in parent-child relations. Journal of Social and Personal Relationships, 14, 44I-46I.

Meeus, W. H. J., Akse, J., Branje, S. J. T., Ter Bogt, T., Delsing, M., Van Doorn, M. D., e.a. (2004). Codeboek van het onderzoeksproject 'Conflict and management of relationships' (CONAMORE) (intern rapport). Utrecht: Universiteit Utrecht, Onderzoeksgroep Adolescentie.

Patterson, G. R. (I982). A social learning approach, Vol. 3. Coercive family process. Eugene, or: Castalia.

Patterson, G. R. (I995). Coercion as a basis for early onset for arrest. In J. McCord (Eds.), Coercion and punishment in long-term perspectives (pp. 8I-I05). Cambridge: University Press.

Patterson, G. R., \& Stouthamer-Loeber, M. (I984). The correlation of family management practices and delinquency. Child Development, 55, I299-1307.

Robin, A. L., \& Foster, S. (I989). Negotiating parent-adolescent conflict: A behavioral-family systems approach. New York: The Guilford Press.

Rubenstein, J. L., \& Feldman, S. S. (I993). Conflict-resolution behavior in adolescent boys: Antecedents and adaptional correlates. Journal of Research on Adolescence, 3, 4I-66.

Sanders, M. R., Dadds, M. R., Johnston, B. M., \& Cash, R. (I992). Childhood depression and conduct disorder, Pt. I. Behavioral, affective, and cognitive aspects of family problem-solving interactions. Journal of Abnormal Psychology, 101, 495-504.

Shek, D. T. L. (I997). The relation of parent-adolescent conflict to adolescent psychological well-being, school adjustment, and problem behavior. Social Behavior and Personality, 25, 277-290.

Shek, D. T. L. (I998). A longitudinal study of the relations between parent-adolescent conflict and adolescent psychological well-being. Journal of Genetic Psychology, 159, 53-67.

Stafford, L., \& Bayer, C. L. (I993). Interactions between parents and children. Newbury Park: Sage.

Tesser, A., Forehand, R., Brody, G., \& Long, N. (I989). Conflict: The role of calm and angry parent-child discussion in adolescent adjustment. Journal of Social and Clinical Psychology, 8, 3I7-330.

Van Doorn, M. D., Branje, S. J. T., \& Meeus, W. H. J. (2009). Regressieanalyse naar conflictoplossingstijlen van adolescenten en hun ouders en delinquentie (intern rapport). Utrecht: Universiteit Utrecht, Onderzoeksgroep Adolescentie. 